\title{
Teaching Reform of Mechanical Drawing Based on Flipped Class
}

\author{
Lichuan Ning ${ }^{1,2, a^{*}}$, Yuanmin Xie ${ }^{1,3, b}$, Guozhang Jiang ${ }^{1,4, c}$, \\ Yan Zhou ${ }^{1,2, \mathrm{~d}}$, Gongfa $\mathrm{Li}^{2,3, \mathrm{e}}$ and Jiabing $\mathrm{Hu}^{3,4, \mathrm{f}}$
}

${ }^{1}$ Key Laboratory of Metallurgical Equipment and Control Technology, Ministry of Education, Wuhan University of Science and Technology, Wuhan 430081, China

2Hubei Key Laboratory of Mechanical Transmission and Manufacturing Engineering, Wuhan University of Science and Technology, Wuhan 430081, China

${ }^{3}$ Research Center of Biologic Manipulator and Intelligent Measurement and Control, Wuhan University of Science and Technology, Wuhan 430081, China

${ }^{4}$ National Machinery Experimental Teaching Demonstration Center, Wuhan University of Science and Technology, Wuhan 430081, China.

a403366762@qq.com, b404438295@qq.com, cwhjgz@wust.edu.cn, d108875266@qq.com, eligongfa@wust.edu.cn, ${ }^{4} 461303771 @ q q . c o m$

\section{Keywords: Mechanical drawing; Flipped classroom; Teaching reform}

\begin{abstract}
As a basic course for mechanical majors, mechanical drawing is the basis of the follow-up related courses which has a very important position. However, the traditional teaching mode is still mainly in the teaching of mechanical drawing, and there are many shortcomings in the traditional teaching mode which is mainly manifested in the lack of activity in the classroom and the poor students' ability to study independently. In view of the above problems, this paper puts forward the reform mode of mechanical drawing teaching based on the overturning class, which leaves the class time to the students fully, and guides the students' ability to find and solve the problems independently. Through the statistical investigation, it is shown that the reform of the mechanical drawing in the flipped classroom is more effective for the students' creativity and the ability to understand the knowledge, and the students' drawing and reading ability are improved on the whole.
\end{abstract}

\section{Introduction}

With the rapid development of the national economy, new engineering talents are becoming more and more important. As an important basic course, mechanical drawing occupies an important position in the training system of mechanical engineering science talents which provides necessary basic knowledge and basic skills for the follow-up course. Mechanical drawing is a subject that uses engineering drawings to express the shape, shape, working principle and other important technical requirements of mechanical products and their parts which be called general language of engineering world [1].This course is a compulsory basic course for most mechanical and related engineering majors in universities. It can help to cultivate students' spatial imagination, image thinking, design and expression, aesthetic and innovation, which could not be replaced by other courses. Therefore, in the mechanical drawing class, we implement the reform of the flipped classroom teaching mode and allocate the class time to the students reasonably. This teaching mode takes students as the center, fully mobilizes the students' independent learning innovation ability, carries out large class teaching, small class discussion, and integrates practical operation into classroom teaching, which can effectively improve students' interest in learning and improve the teaching quality of mechanical drawing courses[2-3].

\section{Present Situation of the Mechanical Drawing Course}

In the early 1980s, Northwest Polytechnic University took the lead in opening the course of cartography and mapping in China, and set up the teaching environment of cartography and 
mapping. Zhejiang University of Technology and other universities have also offered this course for undergraduates majoring in machinery, using centralized teaching methods to survey and map parts. Harbin Institute of Technology and other universities are surveying and mapping courses scattered in the teaching process, rather than centralized teaching. At present, the parts used in surveying and mapping are basically oil pumps and reducers. Students complete part drawings and assembly drawings by ruler drawing [4-5]. Zhengzhou University and other institutions have attempted to introduce two-dimensional computer graphics into mapping. Dalian University of Technology has tried to apply 3D modeling technology to cartography and surveying. In short, mapping and mapping course has been born in China for 30 years, but the existing mapping and mapping experimental teaching is still based on traditional teaching methods.

Most of the existing traditional mechanical teaching models are mainly lectured by teachers. At the same time, most of the mechanical drawing courses have been offered in first grade of college. As new students just come to school in this time, both study and life are in a strange environment, it is easy to produce slack psychology. At the same time, the course of mechanical drawing is rather difficult to understand, which leads to the low interest of the students. In addition, in the existing teaching methods, the practice teaching link is insufficient and the theory and practice teaching are carried out separately. The early stage teaching focuses on the knowledge point and the theoretical system, and the practice is usually carried out only after the end of the theory course. This traditional teaching mode leads to the lack of integration of ability and knowledge, and students' practice time is too short, the ability to improve could not meet the needs of society. In view of the previous teaching practice, a large number of students in the learning of mechanical drawing courses have appeared disjointed by theory and practice, which leads to the poor teaching effect and the phenomenon that the purpose of training is not up to the standard [6-8].

In recent years, flipping class has emerged as a kind of image that subverts the traditional teaching model. It has aroused great repercussions at home and abroad. At present, the overturned classroom reform, which relies on multimedia and network teaching video, has made remarkable achievements both at home and abroad. According to incomplete statistics, dozens of countries have carried out the teaching reform experiment of flipped classroom, and have achieved great success. Through the study, it is known that the conditions for the mechanical drawing to carry out the overturned class are mature, but when the design of the class is turned over which could not simply quote the foreign model, which should be based on the coexistence of the science and art of the course, that is to emphasize the mastery of mechanical drawing knowledge, pay more attention to the improvement of mechanical drawing energy, and design flipped classroom about mechanical drawing which combine knowledge and ability [9].

\section{The Theoretical Connotation of the Flipping Class}

The basic meaning of flipped classroom is the advance of knowledge imparting and the optimization of knowledge internalization brought about by the change of teaching process. In this sense, process elements are only one of the important elements to define flipped classroom. As a real flipped classroom, there are two other elements to be added: technology and environmental factors. The technical element means that the flipped classroom needs micro video to support the students' self-learning [10]. The environmental factors refer to the problem that the flipping classroom needs to continue to analyze the students' learning process in order to improve the quality of the classroom interaction. Therefore, the flipping classroom contains three basic elements: one is the technical elements, mainly for micro video; the two is the process elements, mainly for pre class, class and after class teaching activities; the three is the environmental factors, mainly for the intelligent diagnosis function of the learning analysis system [11]. It is not difficult to see that the context of the overturned class discussed here has changed: the turning class has changed from the focus of the learning place to the whole process of focusing on the teaching activities, and has changed from a single learning behavior to a complex educational behavior that focuses on many factors, such as teachers, students, content, media, and the environment. Focusing on the shift of online video viewing to the student centered rich media environment with the support of intelligent 
diagnostic system, it has changed from the use of information technology to the conscious integration of the whole process of information technology and teaching, and even the awakening of students' spiritual life in the classroom [12]. In this sense, the flipping class should be renamed to flipping teaching, the key is that the relationship, status and function between teachers and students have undergone essential changes. In short, after the introduction of flipped classroom into China, it has changed in content, form and form. Even though it is called flipped classroom, the meaning is completely different. The traditional teaching process usually includes two stages: knowledge imparting and internalization of knowledge. Knowledge imparting is accomplished by teaching in class, and knowledge internalization needs students' homework, operation or practice after class. In the flipped class, this form is subverted, knowledge imparting through the aid of information technology is completed after class, knowledge internalization is completed in the classroom which through the help of the teacher and the help of the students, thus forming a flipped class. With the reversal of the teaching process, all links in the classroom learning process have also changed [13-14].

\section{Application of the Flipped Class in the Teaching of Mechanical Drawing}

With the popularization of computer technology, the flipped class teaching method has come into being. This method readjusts the time inside and outside the classroom, leaving the decision-making power of learning to the students. The teacher's task is to guide and supervise. In this teaching mode, teachers do not use a lot of time to teach basic knowledge, but through the form of micro video to let students study under the class. The valuable time in the classroom is left to the key and difficult questions of teaching and the guidance of the practice of drawing practice. Student exchange. Flip classroom teaching method generally includes four stages: online course editing, student autonomous learning, teacher classroom teaching and assessment feedback.

Online Course Teaching. The course of mechanical drawing and CAD is to study the reading and drawing methods and expressions of the structural diagrams of the stereoscopic model and the mechanical parts and components around the point, line and surface, so as to cultivate the students' reading drawings, drawings and the overall spatial imagination. In the course editor of the mechanical drawing flipping classroom teaching line, we can consider some operating examples of CAD into the teaching of basic knowledge of mechanical drawing, and combine examples with basic knowledge learning. Teachers should select knowledge points according to the abilities of most students, and make clear the learning objectives that students must master. Because there are many knowledge points in the course of mechanical drawing, there are not only theoretical knowledge of descriptive geometry, but also national standards and norms of drawing, and a lot of practical and practice content. At the same time, not all the contents are suitable for flipping class teaching, so the flipping classroom teaching could not be carried out simply according to the chapters on the textbook, It is necessary to reorganize the knowledge points. At the same time, because most of the knowledge points of mechanical drawing are moderately difficult, considering the students' ability for knowledge comprehension, each video should not be too long. The knowledge points of each course should be fragmented, and the length of each video should be 10 to 15 minutes.

Autonomous Learning and Classroom Teaching. The course of mechanical drawing is very important for the cultivation of students' consciousness of engineering and engineering ability. According to the actual needs, the curriculum system based on the "flipped class" is created to change the traditional teaching mode, change the role of teachers, redistribute the time of the class, change the role of the students, and highlight the role of the teachers to lead the passers-by, so that the students can make full use of themselves. The primary consideration is to change the original classroom teaching mode, give the students about $70 \%$ of the class time which make the students take the initiative to participate in the group discussion, question and so on, change the students' angle, leave the $30 \%$ of the class time to the teaching teachers, analyze the difficult and difficult points and answer questions. Emphasis is laid on the integration of knowledge and ability of the "Mechanical Drawing" flip classroom teaching content research, focusing on training students' 
ability for engineering. First, it classifies and integrates the original teaching contents, and each kind of knowledge points according to the depth and detail of the online video courses, reexamines the detailed knowledge points, divides the basic, key and difficult knowledge, and designs the corresponding practical teaching content for each kind of knowledge.

Assessment and Evaluation Mechanism. First, it is necessary to study the weight of each kind of knowledge points in the course system, and to assess the students' understanding and mastery of the knowledge point by the traditional examination method, and consolidate the students' classroom content by using two-dimensional drawing and three-dimensional modeling software, and make the weighted average of the results of each stage of knowledge and ability assessment. As the score of each dimension of knowledge and ability, the final course score is given according to the weight of knowledge and design ability in the course. This method of assessment is guided by the integration of knowledge and ability, embodying scientific and comprehensive in the design of examination content and methods, giving full play to the function of the baton of the evaluation system and improving the overall level of teaching and learning in the reverse direction. As a result, different learning groups can be set up at the same time. Each session will be arranged at a fixed time to discuss the internal problems of the group. Some general questions are given to the instructor, and the questions put forward are prepared. For the teaching design of mechanical drawing flip class, we can design class hours and assign learning tasks according to the three stages of pre-class, in-class and after-class. The process expression is shown in Fig. 1.

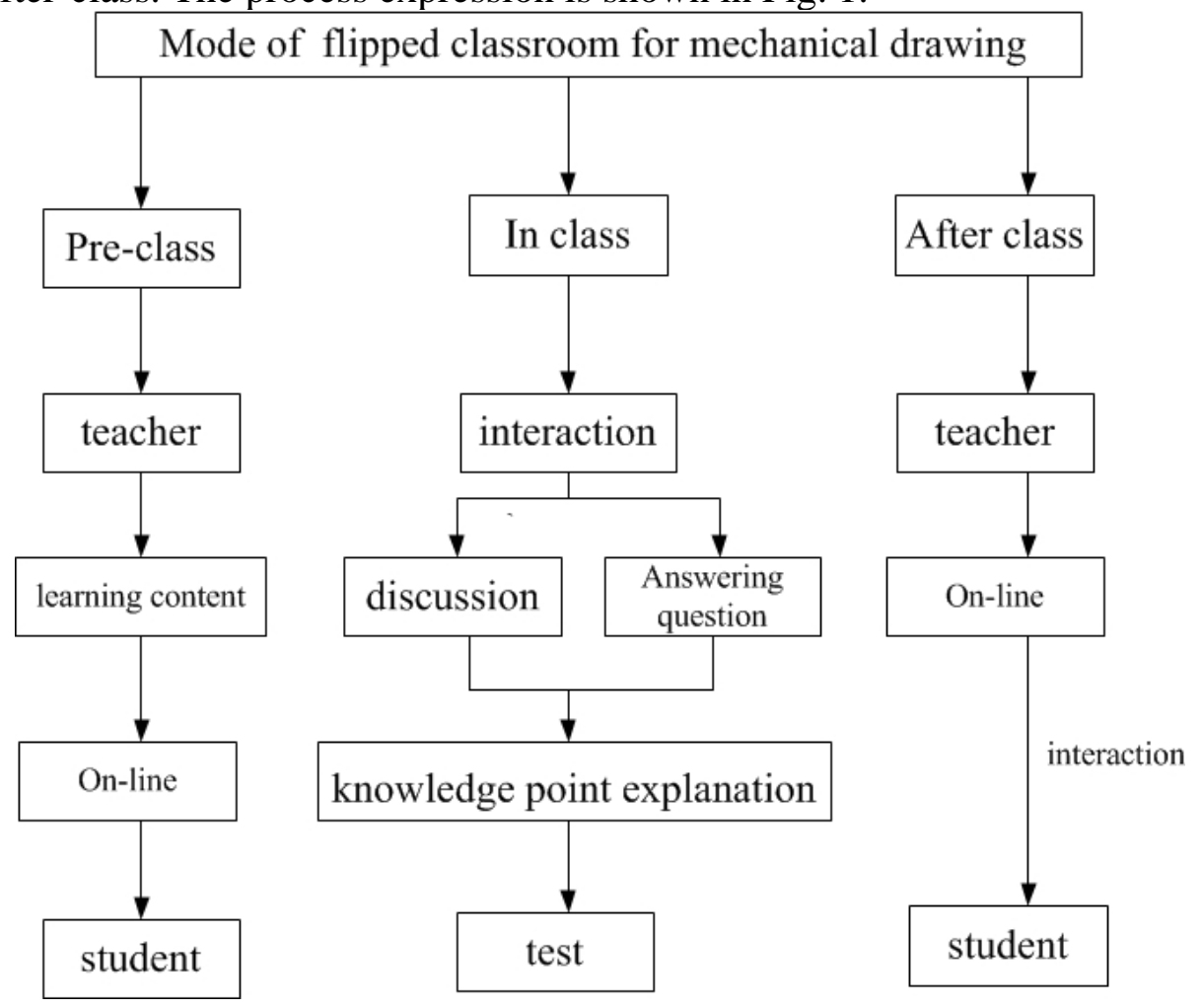

Figure 1. Teaching mode of flipping classroom for mechanical drawing

\section{Teaching Effect}

In two classes, 74 students of mechanical specialties were carried out in the experimental teaching reform of mechanical drawing flipping class. Through the final examination results, teacher's classroom feedback, and the completion of the design drawings, the mechanical majors were compared in the traditional teaching mode. The statistical results show that the students who have been taught in the flipped classroom perform better in the mechanical drawing teaching examination than those who have been taught in the traditional teaching mode. At the same time, the relaxed and active classroom atmosphere provided by the flip-flop class has aroused strong interest in the follow-up courses for mechanical students. 
The flipping classroom teaching method can be a good supplement to the shortcomings of the existing mechanical drawing teaching methods, so that teachers can have a lot of time to guide the students' drawing, exercises and other practical activities in the classroom. However, because the changing of the classroom is not only the means of teaching, but also the way of teaching thinking, it is absolutely impossible to equate the flipped class with video teaching and network teaching. At the beginning of the flipping classroom teaching, teachers need to invest a lot of energy and time to adapt to the new teaching methods, change the mode of thinking, and carefully prepare the teaching materials.

\section{Acknowledgements}

This work was supported by grants of Teaching Research Project of Hubei Province (based on the teaching reform of Mechanical Design) based on the flipping classroom, project number: 2016230; Wuhan University of Science and Technology Graduate Education Reform Research Project (Relying on the School-Enterprise Joint Training Collaborative Center to strengthen the research on the cultivation of mechanical engineering graduate practice and innovation ability, project number: Yjg201610; Research on the mode of postgraduate training for school-enterprise cooperation for masters of mechanical engineering, project number: Yjg201714); Hubei Province Teaching Research Project (2012218; 2013221; 2015234; 2016230); Teaching Research Project of Wuhan University of Science and Technology (2013059)

\section{Reference}

[1] J. Cheng, Y. L. Wang and D. Tjondronegoro: International Journal of Emerging Technologies in Learning, Vol. 13 (2018) No.12, p.126.

[2] R. K. Desu, S. K. Singh and A. K. Gupta: International Journal of Advanced Manufacturing Technology, Vol. 85 (2016) No.1, p.661-672.

[3] J. T. Li, X. S. Jia, and G. F. Yu: Nanoscale Research Letters, Vol. 11 (2016) No.1, p.426.

[4] G. Baronio, B. Motyl, and D. Paderno: Computer Applications in Engineering Education, Vol. 24 (2016) No.4, p.519-528.

[5] Y. Hao: Computers in Human Behavior, Vol. 59 (2016) p.82-89.

[6] B. Sohrabi and H. Iraj: Computers in Human Behavior, Vol. 60 (2016) p.514-524.

[7] R. Yilmaz: Computers in Human Behavior, Vol. 70 (2017)

[8] Y. Hao and K. S. Lee: Computers in Human Behavior, Vol. 57 (2016) p.250-260.

[9] J. Mehring: Computers in the Schools, Vol. 33 (2016) No.1, p.1-10.

[10] J. Wang, J. Min and Y. Lv: Computers in Human Behavior, Vol.84 (2018).

[11] L. Shu, G. Li and X. Cao: Boletin Tecnico/technical Bulletin, Vol. 55 (2017) No.11, p.672-678.

[12] M. Mavromihales and V. Holmes: International Journal of Mechanical Engineering Education, Vol. 44 (2016) No.2.

[13] C. W. Tsai, P. D. Shen and Y. C. Chiang. Universal Access in the Information Society, Vol. 16 (2016) No.1,p1-9.

[14] A. Kashada, H. Li and C. Su: International Journal of Emerging Technologies in Learning, Vol. 12 (2017) No.10.p.147. 